\title{
Nilai Dasar Collaborative Governance Dalam Studi Kebijakan Publik
}

\author{
Nasrulhaq $^{1 *}$ \\ ${ }^{1}$ Ilmu Administrasi Negara, Universitas Muhammadiyah Makassar, Indonesia
}

\begin{abstract}
This paper examines the basic values of collaborative governance based on theoretical studies and empirical facts in an integrative manner. The starting point study of the relationship between stakeholders in each stage of public policy is increasingly complex. Based on this complexity, studies on governance also experience dynamics. The collaborative framework in governance provides a meaning that is more than just governance. Collaborative governance is a concept in public policy that has developed in the last few decades. In principle, the collaborative is different from the network as well as the partnership. There is an essential value attached to it. Henceforth, it becomes part of its characteristics. The basic values referred to are consensus orientation, collective leadership, multidirectional communication, and resource sharing. The four basic values are integrated into one integrated process in any collaborative governance action.
\end{abstract}

Keywords: value, collaborative governance, public policy

\begin{abstract}
Abstrak
Tulisan ini mengkaji secara integratif nilai dasar collaborative governance yang didasarkan pada kajian teoritik dan fakta empirik. Kajian bertitik tolak dari fenomena hubungan antara pemangku kepentingan dalam setiap tahapan kebijakan publik yang semakin kompleks. Atas dasar kompleksitas tersebut, kajian tentang governance juga mengalami dinamika. Kerangka collaborative dalam governance memberikan suatu pemaknaan yang lebih dari sekedar governance. Collaborative governance merupakan salah satu konsep dalam kebijakan publik yang berkembang dalam beberapa dekade terakhir. Secara prinsip, collaborative (kolaborasi) berbeda dengan network (jaringan) dan partnership (kemitraan). Ada nilai dasar tersendiri yang melekat padanya. Untuk selanjutnya menjadi bagian karakteristiknya. Adapun nilai dasar yang dimaksud yakni orientasi konsensus, kepemimpinan kolektif, komunikasi multiarah dan berbagi sumber daya. Keempat nilai dasar menyatu menjadi satu kesatuan proses dalam setiap aksi collaborative governance.
\end{abstract}

Kata Kunci: nilai, collaborative governance, kebijakan publik

\footnotetext{
*nasrulhaq@unismuh.ac.id

DOI: https://doi.org/10.26618/kjap.v6i3.2261
} 


\section{PENDAHULUAN}

Dalam beberapa tahun terakhir, collaborative governance (tata kelola pemerintahan) menjadi salah satu konsep kepublikan yang mulai banyak diminati oleh para akademisi. Ini ditandai dengan meningkatnya tulisan serta publikasi, baik luar negeri maupun dalam negeri, bertemakan kolaborasi. Collaborative Governance muncul untuk merespon terjadinya kegagalan implementasi, biaya mahal dan politisasi regulasi sektor publik (Ansell \& Gash, 2008). Fokusnya mengarah pada setiap tahapan kebijakan publik. Beberapa penulis telah mengilustraikannya dengan berbagai macam pemaknaan. Gray dkk (2003) menyebutnya sebagai instrumen kebijakan publik. Jung dkk (2009) Jung dkk (2009) menyebutnya sebagai kunci pendekatan kelembagaan. Apapun pemaknaan yang dialamatkan para pakar terdahulu, konsep ini merupakan tema strategis dalam administrasi publik menurut Emerson dkk (2012). New governance harus dikaji lebih mendalam agar fenomena yang ada bisa dipahami secara komprehensif.

\section{Collaborative}

governance

merupakan sebuah paradigma baru dalam memahami eksistensi multi stakeholders dalam urusan-urusan publik. Ada karakteristik tertentu dalam hubungan aktor sehingga penting melakukan studi kolaborasi (Silvia, 2011). Kolaborasi dimaknai berbeda dari jaringan (network) dan kemitraan (partnership). Menurut Ansell \& Gash (2008), jaringan digunakan untuk menggambarkan bentuk kerjasama pemerintah dengan masyarakat yang lingkupnya lebih plural, informal dan implicit. Kemitraan digunakan untuk menggambarkan kerjasama yang lebih berorientasi pada koordinasi daripada konsensus dalam pengambilan keputusan. Kolaborasi digunakan untuk menggambarkan kerjasama yang formal, eksplisit dan berorientasi kolektif dalam pengambilan keputusan. Kolaborasi melibatkan pengelolaan hubungan untuk memanipulasi regulasi dan sistem sementara jaringan hanya berbicara pada pelaksanaan pekerjaan sipil (Goliday, 2010). Kemitraan terjadi ketika agen private kurang lebih menggantikan peran publik sedangkan kolaborasi terjadi ketika agen public dan private melakukan fungsifungsi aktif (Bevir, 2009).

Collaborative governance sebagai bentuk new public governance mempunyai nilai dasar. Nilai dasar itulah yang menjadi karektiristiknya sekaligus muatan pokoknya. Dengan kata lain, nilai dasar itulah yang menjadi titik tekannya. Ada penekanan yang penting dipahami untuk memudahkan dalam menganalisis suatu fenomena sekaligus membuat sebuah teori baru tentang administrasi dan kebijakan 
publik. Perlu ada pencerahan untuk memahami apakah fenomena yang ada berwujud collaborative governance atau tidak. Jangan sampai ada kekeliruan yang terjadi dalam kajian teoritik dan empirik. Melalui tulisan ini, dijelaskan empat nilai dasar yakni:

1. Orientasi konsensus, poin ini menjelaskan tujuan collaborative governance.

2. Kepemimpinan kolektif, poin ini menjelaskan bentuk struktur kelembagaan collaborative governance.

3. Komunikasi multi arah, poin ini menjelaskan interaksi antar aktor dalam proses collaborative governance.

4. Berbagi sumber daya, poin ini menjelaskan proses yang terjadi selama aksi collaborative governance.

\section{METODE PENELITIAN}

Artikel ini dibuat dengan menggunakan metode penelitian kepustakaan (library research). Prosesnya dilakukan dengan pendekatan yang simple atau kurang sistematis. Penulis menganalisis beberapa tulisan yang terkait dengan collaborative governance dalam studi kebijakan publik dari beberapa artikel jurnal dan buku bereputasi sebagaimana yang tercantum dalam daftar pustaka (referensi).

Proses penulisan dan analisisnya dilakukan dengan beberapa tahapan yakni penelusuran artikel pada jurnal dan buku secara online dan offline, pengumpulan dan pengkodean referensi pada aplikasi Mendeley, penganalisaan artikel secara manual dan integratif pada Microsoft Word, penerimaan saran dan masukan secara open review di research gate pada link https://www.researchgate.net/publication/3 25259052_NILAI_DASAR_COLLABOR ATIVE_GOVERNANCE_DALAM_STU DI_KEBIJAKAN_PUBLIK.

\section{HASIL DAN PEMBAHASAN}

\section{Orientasi Konsensus}

Menurut Kamus Besar Bahasa Indonesia, konsesus merupakan kesepakatan kata atau pemufakatan bersama (mengenai pendapat dan pendirian) yang dicapai melalui kebulatan suara. Konsensus dijunjung tinggi karena gambaran pokok kolaborasi adalah kesepakatan bersama. Aksi yang dilakukan berawal dari adanya satu tekad dan satu tujuan. Kepentingan setiap invidu atau organisasi terakumulasi menjadi kepentingan bersama. van Oortmerssen dkk (2015) menjelaskan bahwa orientesi konsensus sangat dibutuhkan dalam 
kolaborasi multipihak. Beberapak pakan menyebutkan bahwa bukan wujud kolaborasi kalau pengambilan keputusannya tidak dalam bentuk konsensus. Inilah item perbedaan utama dengan pendekatan lainnya yang juga menjelaskan hubungan antara multipihak. Hal yang dikonsensuskan menyangkut semua persoalan yang terkait dengan suatu kebijakan atau program. Baik yang telah ditetapkan sebelumnya maupun persoalan yang sementara dan akan dilakukan.

Oleh Ansell \& Gash (2008) dalam tulisannya yang berjudul 'Collaborative Governance In Theory and Practice', kriteria kolaborasi adalah konsensus. Persetujuan dilandasi pada kepentingan bersama. Konsensus menjadi penting karena governance menggambarkan interaksi minimal dua pihak. Semakin banyak pihak yang terlibat maka semakin dinamis konsensus yang terjadi. Tidak ada keputusan yang diambil oleh satu atau sebagian saja pihak saja. Pernyataan umumnya, menurut Provan \& Kenis (2008), penyelesaian masalah berbasis konsensus lebih baik dilakukan untuk menghindari adanya konflik. Hubungan berbasis kolaborasi rentan terhadap konflik sehingga konsensus menjadi hal yang harus dikedepankan. Baik atau buruknya kolaborasi bisa dilihat dari sejauhmana kesepakatan bersama dilakukan. Kalau putusan yang diambil didominasi oleh kelompok tertentu tanpa musyawarah mufakat, itu menandakan adanya masalah dengan kolaborasi.

Konsensus harus dilandasi dengan komitmen. Muatan komitmen terkait dengan pengawalan janji atau kesepakatan. Tanpa komitmen yang tinggi, sulit mewujudkan kesatuan janji. Disamping itu, hal yang menentukan sebuah konsensus tergantung pada simbiosis mutalisme (saling menguntungkan). Apabila ada pihak yang dirugikan, peluang tidak tercapainya konsensus sangat besar. Jadi, saling komitmen dan saling menguntungkan penting dikedepankan agar orientasi dapat tercapai dengan baik. Memang tidak mudah mencapai pemufakatan bersama karena banyak kepentingan dalam sebuah collaborative governance. Berbeda organisasi terkadang berbeda kepentingan.

\section{Kepemimpinan Kolektif}

Salah satu tema pokok dalam praktek kolaborasi menurut Osborne (2010) adalah leadership (kepemimpinan). Emerson $\mathrm{dkk}$ (2012) menambahkan bahwa kepemimpinan merupakan bagian dari kapasitas aksi bersama dalam praktek collaborative governance. Aspek kepemimpinan menjadi salah satu nilai dasar beranjak dari pemahaman bahwa inti manajemen dan tata kelola adalah

\section{c) sîntå}


kepemimpinan. Kepemimpinan dalam kolaborasi lebih berbentuk jaringan daripada hierarki. Artinya, setiap pihak berada pada posisi yang sama. Hubungan pihak yang terlibat lebih pada fungsi koordinasi daripada komando. Berbeda dengan pola hierarki yang biasanya lebih mengedepankan komando. Posisi aktor sama secara struktural. Tidak ada yang berada diatas ataupun dibawah. Garis koordinasinya tidak vertikal. Masingmasing memiliki tugas yang berbeda tetapi berada pada posisi yang sama. Tugas dan tanggungjawab dilakukan secara berkala.

Pemahaman kepemimpinan dalam kolaborasi diarahkan pada kepemimpinan kolektif. Semua aktor invidu, kelompok atau organisasi yang terlibat berstatus pemimpin tanpa terkecuali. Istilah kepemimpinan kolektif senada dengan istilah distribusi kepemimpinan seperti yang dikemukakan oleh Martin dkk (2009). Meskipun diarahkan pada model kolektif, kehadiran koordinator tetap dianjurkan untuk memudahkan pengarahan. Setidaknya menjadi pusat dari tahapan kebijakan publik untuk mengetahui kemajuan, hasil dan dampak. Saling berkoordinasi merupakan poin yang sangat penting. Sebagaimana telah dijelaskan sebelumnya, kebersamaan mendapat prioritas yang tertinggi. Oleh karena itu, saling koordinasi tidak bisa dihindari. Itulah alasannya sehingga kepemimpinan kolektif berbasis jaringan menjadi salah satu nilai dasar. Kepemimpinan kolektif bentuk dari distribusi kekuatan diantara para pemangku kepentingan menurut Johnston dkk (2011). Kepemimpinan kolektif sebagai nilai dasar kolaborasi tetap berlangsung dari tahap formulasi sampai evaluasi kebijakan publik (Jung dkk, 2009).

\section{Komunikasi Multiarah}

Ansell \& Gash, (2008) menempatkan komunikasi menjadi salah satu proses inti dalam kolaborasi. Mereka menggambarkan dalam bentuk dialog tatap muka. Komunikasi dalam poin ini kelanjutan dari nilai dasar sebelumnya, yakni kepemimpinan kolektif. Cline (2000) menyatakan bahwa komunikasi merupakan subsistem dari implementasi kebijakan. Dalam kolaborasi dibutuhkan adanya komunikasi multiarah. Komunikasi multiarah yakni adanya umpan balik yang berlangsung dengan melibatkan lebih dari dua pihak yang berlangsung secara berkelanjutan dengan intensitas yang tinggi. Respon dan tanggapan dilakukan pada semua pihak yang terlibat dengan berbagai macam cara berkomunikasi (lisan atau tulisan). Collaborative governance yang ideal setidaknya mengikutsertakan minimal dari tiga pihak. Ada representasi 
pemerintah, swasta dan masyarakat. Komunikasi yang dilakukan melalui tatap muka langsung. Komunikasi melalui media dilakukan hanya untuk membantu terjalinnya komunikasi intensif. Adanya interaksi langsung dapat memberikan penguatan pada nilai dasar yang lain. Pada akhirnya memperkuat praktek kolaborasi.

Interaksi antar aktor memang perlu berlangsung maksimal. Komunikasi yang baik akan menggerakkan human relation yang baik pula. Terjalinnya pesan yang efektif dari satu komunikan ke komunikan yang lain dapat berdampak pada penguatan interaksi berbasis kolaborasi. Komunikasi multiarah dijadikan salah satu nilai dasar untuk menggambarkan bahwa dalam kolaborasi ada sesuatu yang lebih pada hubungan antar aktor. Lebih lanjut, persoalan yang paling utama dalam komunikasi adalah kotennya. Hal yang menjadi pesan setidaknya terkait dengan curah pendapat dan berbagi informasi. Norris-Tirrell \& Clay (2010) menjadikan komunikasi sebagai salah satu indikator untuk menilai tingkatan kolaborasi. NorrisTirrell \& Clay, (2010) membagi tinggkatan kolaborasi dengan 5 yaitu eksplorasi, formasi, tumbuh, dewasa dan akhir. Singkatnya, lintas pihak harus saling berkomunikasi langsung untuk menguatkan praktek collaborative governance.

\section{Berbagi Sumberdaya}

Sumber daya yang dimaksud yakni sumber daya manusia dan sumber daya keuangan serta sumber daya lainnya yang dapat memperkuat aktfitas kolaborasi dalam kebijakan publik. Emerson dkk, (2012) menempatkan sumber daya sebagai bagian dari variabel kapasitas. Kapasitas kolaborasi dapat dilihat pada sejauhamana sumber daya dibagi dan terbagi. Harapannya dengan cara itu, setiap kolaborator bisa saling menguatkan kelebihan dan menutupi kekurangan serta sama-sama aktif bertindak. Saling menguatkan dan saling menutupi, sebenarnya, esensi sebuah aktifitas kolaborasi. Pendekatan kolaborasi dilakukan untuk memudahkan pemecahan masalah publik. Harus diakui bahwa pemerintah memiliki kelebihan dan kelemahan, begitupun dengan swasta, media dan lembaga swadaya masyarakat. Kolaborasi hadir untuk menjawab adanya kekurangan sumber daya. Seringkali kekurangan sumber daya menjadi alasan tidak dilaksanakannya suatu pemecahan masalah.

Kinerja lembaga sangat dipengaruhi oleh sumber dayanya (Lee \& Whitford, 2013). Collaborative governance yang telah dijadikan strategi governance memang harus memperhatikan sumber daya dalam rangka penguatan kebijakan 
publik. Adanya pembagian sebagaimana yang diutarakan tentu akan menjadi kekuatan tersendiri. Sebagai tambahan, pengetahuan juga termasuk hal yang harus dibagi. Apabila kebutuhan sumber daya terpenuhi, dampak dari sebuah aksi kolaborasi akan lebih terasa. Sudah pasti kekuatan yang dimiliki oleh kolaborasi lebih baik dibanding aktivitas yang parsial. Sesuatu yang menyatu dan disatukan memiliki kekuatan tersendiri. Forum kolaborasi sudah menjadi milik bersama semua pihak yang terlibat. Oleh karena itu, tidak ada alasan untuk tidak membagi sumber daya yang dimiliki. Hasil yang baik akan meningkatkan reputasi pihak yang terlibat, sebaliknya hasil yang buruk akan menurunkan reputasi. Sudah pasti, kolaborasi hadir untuk memberikan warna yang lebih baik. Berbagai sumber daya menjadi salah satu penopangnya.

\section{KESIMPULAN}

Kompleksnya hubungan antara aktor dalam kebijakan publik melahirkan konsep baru yang dinamakan collaborative governance. Ringkasnya, collaborative governance adalah proses dan struktur yang melibatkan berbagai pihak melintasi batas-batas organisasinya. Kolaborasi digunakan untuk menggambarkan kerjasama yang formal, aktif, eksplisit dan berorientasi kolektif dalam manajemen dan kebijakan publik. Adapun nilai dasarnya yakni orientasi konsensus dalam pengambilan keputusan (tujuan), kepemimpinan kolektif dalam kelembagaan (struktur), komunikasi multiarah dalam hubungan kemanusiaan (interaksi) dan berbagi sumber daya dalam aksi (proses). Nilai dasar tersebut menjadi satu kesatuan yang terintegrasi pada setiap tahapan kebijakan publik.

\section{DAFTAR PUSTAKA}

Ansell, C., \& Gash, A. (2008). Collaborative governance in theory and practice. Journal of Public Administration Research and Theory, 18(4),

543-571. https://doi.org/10.1093/jopart/mum03 2

Bevir, M. (2009). Key Concepts in Governance. Sage Publication.

Cline, K. D. (2000). Defining the Implementation Problem: Organizational Management versus Cooperation. Journal of Public Administration Research and Theory, 10(3), 551-571. https://doi.org/10.1093/oxfordjournals .jpart.a024281

Emerson, K., Nabatchi, T., \& Balogh, S. (2012). An integrative framework for collaborative governance. Journal of Public Administration Research and Theory, 22(1), 1-29. https://doi.org/10.1093/jopart/mur011

Goliday, A. M. (2010). Identifying the relationship between network governance and community action program participation (Vol. 3412973) [Walden University]. http://search.proquest.com/docview/7 46615990 ? accountid $=13552 \% 5 \mathrm{Cnhtt}$ p://primo-direct- 
apac.hosted.exlibrisgroup.com/openur 1/RMITU/RMIT_SERVICES_PAGE? ?url_ver=Z39.88-

2004\&rft_val_fmt=info:ofi/fmt:kev:m tx:dissertation \&genre $=$ dissertations + $\% 26+$ theses\&sid=ProQ:P

Gray, Andrew; Jenkins, Bill; Leeuw, Frans; Mayne, J. (2003). Collaboration in Public Services: The Challenge for Evaluation (Comparative Policy Evaluation). Transaction Publishers.

Johnston, E. W., Hicks, D., Nan, N., \& Auer, J. C. (2011). Managing the inclusion process in collaborative governance. Journal of Public Administration Research and Theory, 21(4), 699-721. https://doi.org/10.1093/jopart/muq045 Jung, Y.-D., Mazmanian, D., \& Tang, S.Y. (2009). Collaborative Governance in the United States and Korea: Cases in Negotiated Policymaking and Service Delivery. International Review of Public Administration, 13(sup1), 1-11.

Lee, S.-Y., \& Whitford, A. B. (2013). Assessing the Effects of Organizational Resources on Public Agency Performance: Evidence from the US Federal Government. Journal of Public Administration Research and Theory, 23(3), 687-712.

Martin, G. P., Currie, G., \& Finn, R. (2009). Leadership, Service Reform, and Public-Service Networks: The Case of Cancer-Genetics Pilots in the English NHS. Journal of Public
Administration Research and Theory, 19(4), 769-794.

Norris-Tirrell, D., \& Clay, J. A. (2010). Strategic Collaboration in Public and Nonprofit Administration: A PracticeBased Approach to Solving Shared Problems. CRC Press: Taylor \& Francis Group.

Osborne, S. P. (2010). The New Public Governance?: Emerging Perspectives on the Theory and Practice of Public Governance. Routledge. https://doi.org/10.4324/97802038616 84

Provan, K. G., \& Kenis, P. (2008). Modes of network governance: Structure, management, and effectiveness. Journal of Public Administration Research and Theory, 18(2), 229252.

https://doi.org/10.1093/jopart/mum01 5

Silvia, C. (2011). Collaborative Governance Concepts for Successful Network Leadership. State and Local Government Review, 43(1), 66-71. https://doi.org/10.1177/0160323x114 00211

van Oortmerssen, L. A., van Woerkum, C. M. J., \& Aarts, N. (2015). When Interaction Flows: An Exploration of Collective Creative Processes on a Collaborative Governance Board. Group and Organization Management, 40(4), 500-528. https://doi.org/10.1177/10596011145 60586

\section{C) sîntå}

